\title{
The uniform information virtual space of construction organizations as an effective control of the construction process management
}

\author{
Alena Antipova ${ }^{1 *}$, Daria Eremina $^{1}$, and Tatiana Shakirova ${ }^{1}$ \\ ${ }^{1}$ Tyumen Industrial University, Volodarskogo str., 38, Tyumen, 625000, Russia
}

\begin{abstract}
In the face of new modern requirements for the construction industry, the need for prompt and timely interaction between departments involved in the construction of buildings and facilities has increased. The structural analysis of processes at each stage of the construction life cycle determined the need to form a uniform information virtual space for the organizational structures involved in the construction of objects of various levels. During the research the features of the interaction of construction organizations and enterprises with the customer are studied, an algorithm for interaction between participants in the construction process in the uniform virtual space and an information model of the virtual space of construction organizations and enterprises is implemented. The structure of the information system is a client-server architecture and allows to track the progress of construction step by step, maintain electronic document management and receive services in electronic format. The uniform virtual platform will unite all participants in the construction process: investors, customers, design and survey institutes, government agencies and construction organizations. The proposed regulations will allow to create a completely new process approach to the system of interaction between the participating structures and the operational control system at each stage of the life cycle as well as help unite all participants in the construction process, provide them timely access and reliable access to sources of information about the facility.
\end{abstract}

\section{Introduction}

The development of the construction industry is one of the defining tasks of the government. The modern construction market forms a number of completely new tasks that require all participants to be responsive, flexible and optimal approaches for the implementation of the entire process for obtaining modern buildings that meet all the requirements of buildings and structures. The solution of these tasks is possible only considering the effective management and high-quality information and technical support of interaction of all government structures involved in the construction process. Very often there is a communication failure between the participants of the process due to the lack of a clear mechanism of interaction which brings a shift in the timing of the project, the need for

*Corresponding author: alena_ant@_rambler.ru 
additional costs and leads to a deterioration in the quality of the final product. In this regard it is necessary to implement such a comprehensive solution that will allow to form a completely new information approach to the system of interaction and control and help to unite all the participants in the construction process to become the only true and complete source of information about the facility [1].

\section{Materials and Methods}

The analysis of existing software in the construction industry showed that most information systems do not fully provide a comprehensive approach in the interaction between all participants of the process at each stage of the life cycle of the construction site $[2,3,4]$. In addition there is no well-defined process control at all stages of the construction life cycle using integrated information support implementing the formation of intra-organizational and inter-organizational communication links between all project participants. Despite the seeming simplicity of the existing interaction scheme a large number of problems arise at the stage of collection and coordination of all the necessary documentation. During the entire life cycle of the facility, the customer turns to the government structures that provide control at the relevant stage of construction $[5,6,7]$. The best solution for this problem is the formation of the uniform virtual space of construction organizations and enterprises that would unite all participants of the construction process in the information space: investors, customers, design and survey institutes, government structures and construction organizations [8].

For the implementation of the uniform virtual space a study was made of the characteristics and features of construction organizations and enterprises on the example of the Tyumen region $[9,10]$. Based on the analysis of the software used in construction organizations the decision is made to develop the uniform virtual space which will provide a reliable source of information and increase the speed of data processing and ensure the promptness of making managerial decisions.

An important stage in the development of information systems is a thorough description of all automation processes and the relationship between them. For detailed analysis of the implemented life cycle processes in construction a structural approach to the design of the basic elements of the information model is considered, based on the IDEF0 methodology [11, 12, 13].

When constructing the diagram the following main subprocesses were identified (Figure 1):

- Pre-project preparation - at this stage of the work there is a choice of the land plot, obtaining ownership of it and technical conditions for engineering and construction surveys and their further implementation.

- The design stage-based on the data obtained after the survey the project documentation is developed, its expertise is carried out and the request for a construction permit for this object is submitted.

- Construction works - after obtaining a construction permit the customer enters into an agreement with one of the construction companies which becomes the main contractor. The main contractor, in turn, can conclude an agreement with several other companies to carry out certain types of work. The control over the compliance of the project documentation and the work to be performed is entrusted to the General Department of Construction. The result of this management is the issuance of an act on the conformity of the constructed object and the documentation. After that a request is made to obtain a permit for putting the facility into operation and commissioning is performed.

- Operation- monitoring of various indicators of the construction site during the use of its operation. Based on these indicators a decision can be made about overhaul, reconstruction or decommissioning of the facility. 
- Disposal of the object - the expert commission makes a conclusion about the impossibility of further operation of the building and sends a request to the City Department for permission to decommission the facility.

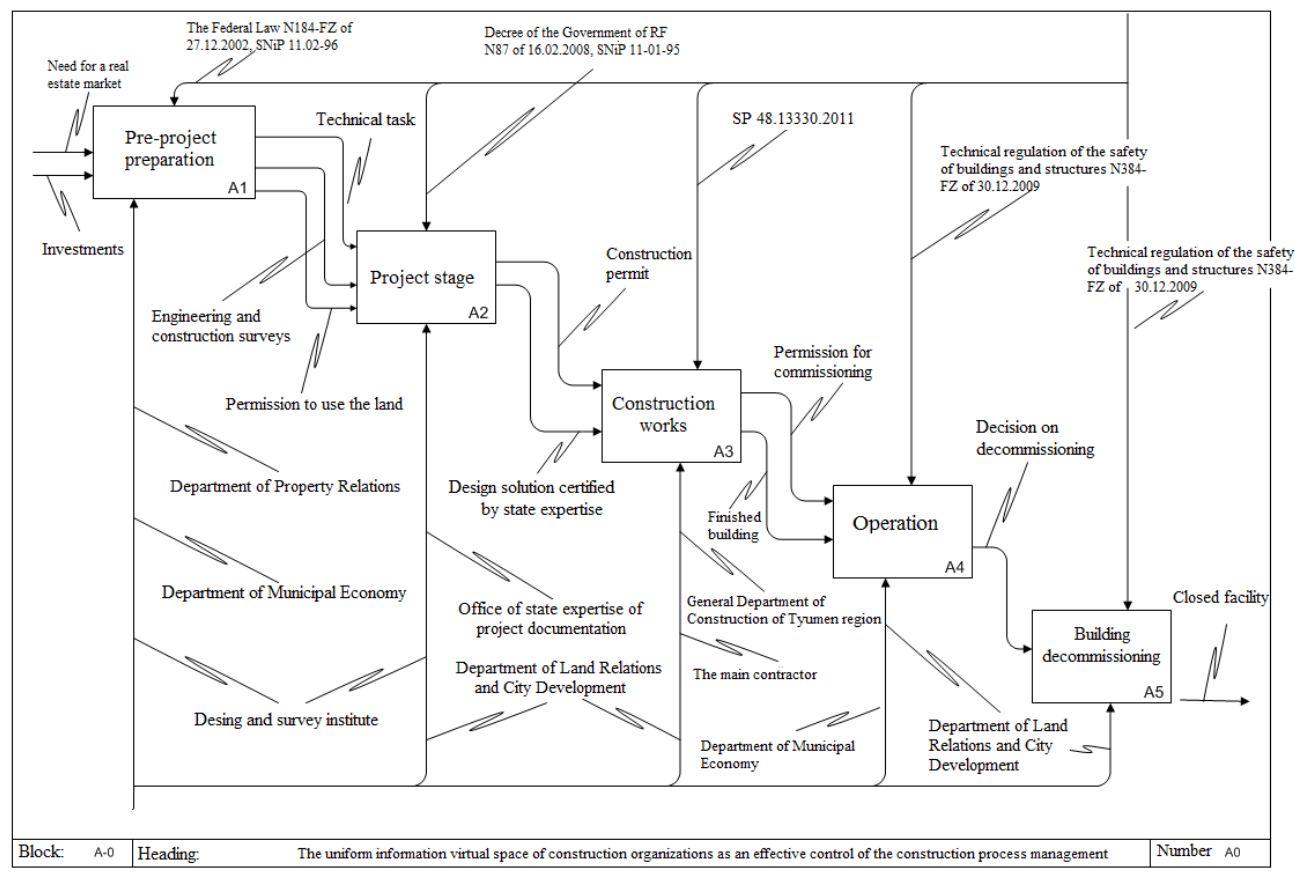

Fig.1. Decomposition of the first level

Dozens are involved in the construction of any facility and in the construction of large structures - and hundreds of enterprises and organizations whose financial resources, one way or another, participate in construction. Despite the fact that the ultimate goal for all participants of the investment process is to obtain the maximum possible profit in the process of construction each of the participants has its own goals and objectives. Considering this there arises the need to define criteria that would unite all the participants of the investment process to achieve a single goal - completion of construction at a given time with minimal costs and a high level of quality [14].

In the scheme of interaction between the participants of the construction process three groups of objects can be distinguished: organizers, controlling bodies and information resources. The diagram is shown on Figure 2. 


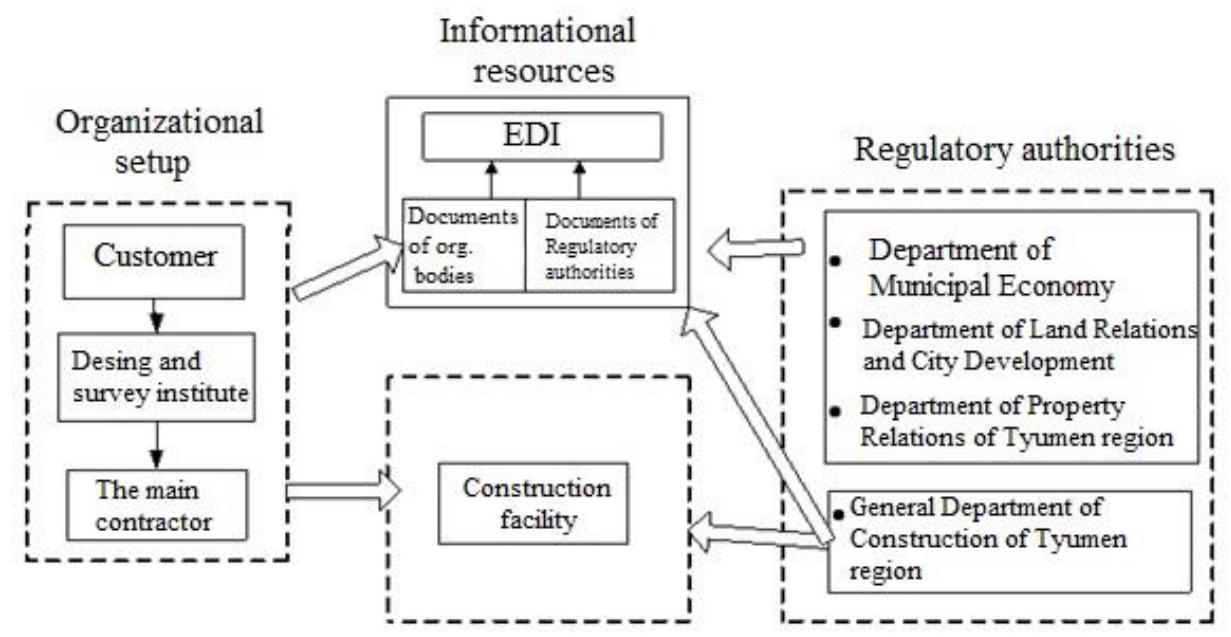

Fig. 2. Organizational model of participants in the construction process

The organizational structure includes the customer, the design and survey institute and the main contractor. These parties are engaged in collecting documentation that accompanies the construction at all stages.

The controlling public services control the issuance of permits, conditions and other documentation. The General Department of Construction largely controls the construction process directly. The information resources contain data, information and knowledge recorded on appropriate media. These three components should ensure high-quality information interaction of all participants in the process.

The interaction of parties in the uniform virtual space begins from the moment when the customer adds a new building object to the list of controlled building projects in his personal page. He enters the data about the purpose of the project, the designation of the structure and other information which is consolidated during the analysis of the real estate market and is the basis for the decision to implement this project. A unique identifier is assigned to the object which in the future should be in all documents associated with this project [15]. The further algorithm of interaction of the process participants is shown on Figure 3.

The implementation of the interaction algorithm takes place according to the script previously described in the system. A so-called checklist of the object is formed which includes a list of the main documentation that accompanies the building object throughout its life cycle.

To obtain the relevant documents there are certain scenarios that determine the functional interaction of all modules of the information space. The system will provide an opportunity to proceed to the next stage only after filling the checklist of the previous level. The customer will not be able to proceed with the conclusion of a contract with a design and survey institute if he has not received technical conditions for a land plot for which he already owns ownership [16].

The first stage in the interaction of construction organizations is the creation of a request for the provision of the necessary land plot for the customer. When a complete list of documents is formed it is automatically sent to an organization which issues such documents. The request comes to one of the specialists of the department, he examines the documents. In terms of the prescribed scenario the refusal to provide services due to the incompleteness of the provided documents is automatically excluded. Each organization has its own document store. Therefore, the customer has only an image or a link to the received document 
which any of the parties entering the information space can access, according to their access rights.

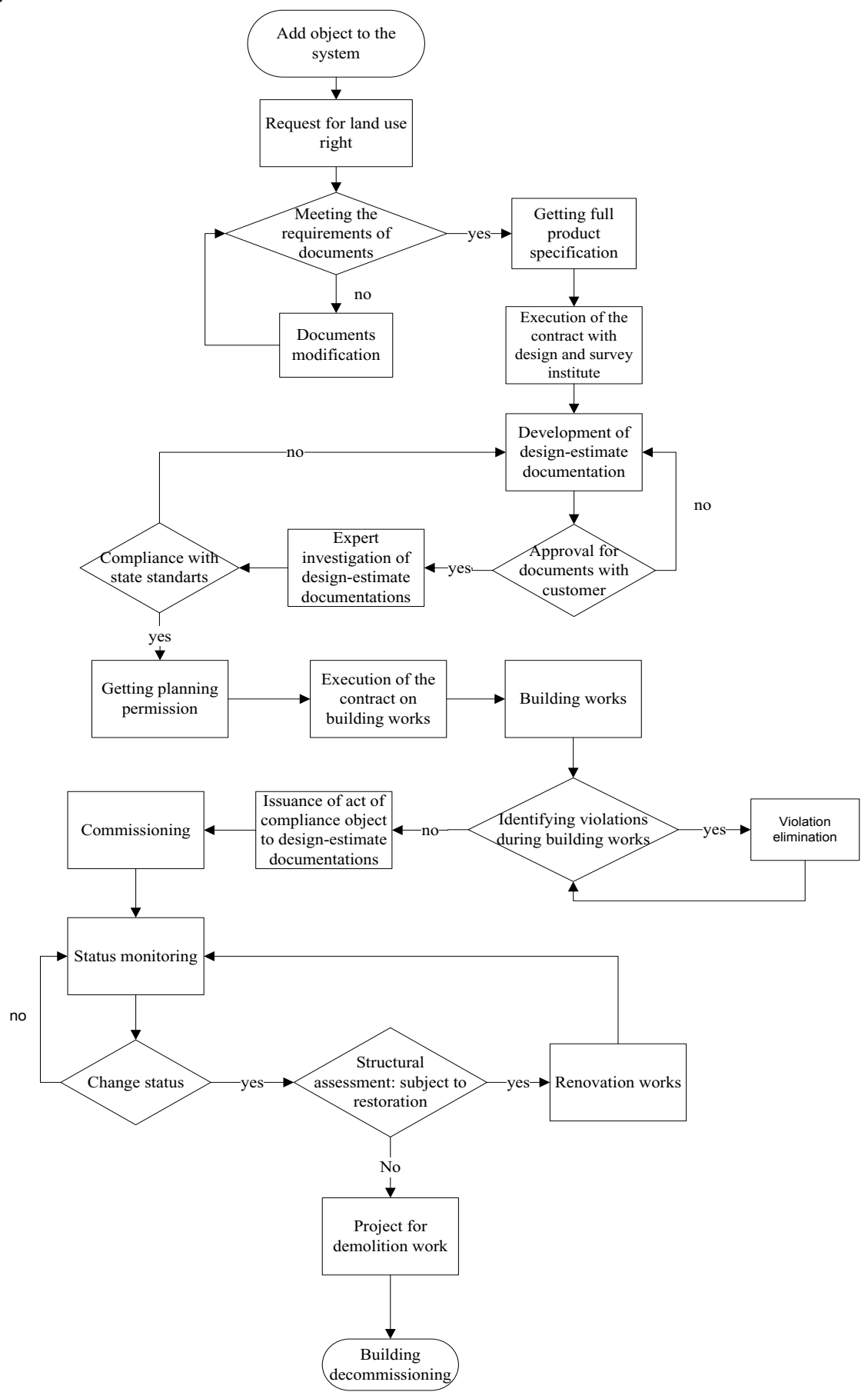

Fig.3. Algorithm of interaction of construction organizations and enterprises in the uniform virtual space 
During the operation of the building it is necessary to monitor its technical condition. This function is assigned to the City Department. Based on the results of the inspection a report about the technical condition of the facilities prepared and the decision is made whether the building is suitable and is able to perform its functions and meet all safety requirements. In the case when deviations are not significant restoration work is carried out. Otherwise the project is being developed for the demolition of the building and its decommissioning is taking place.

\section{Results}

The project of the uniform information space (Figure 4) is a collection of databases, information, knowledge and technologies for its maintenance and use, information systems and telecommunications networks operating on the basis of common principles and general rules of providing information interaction of organizations and individuals and also satisfaction of their information needs [17, 18].

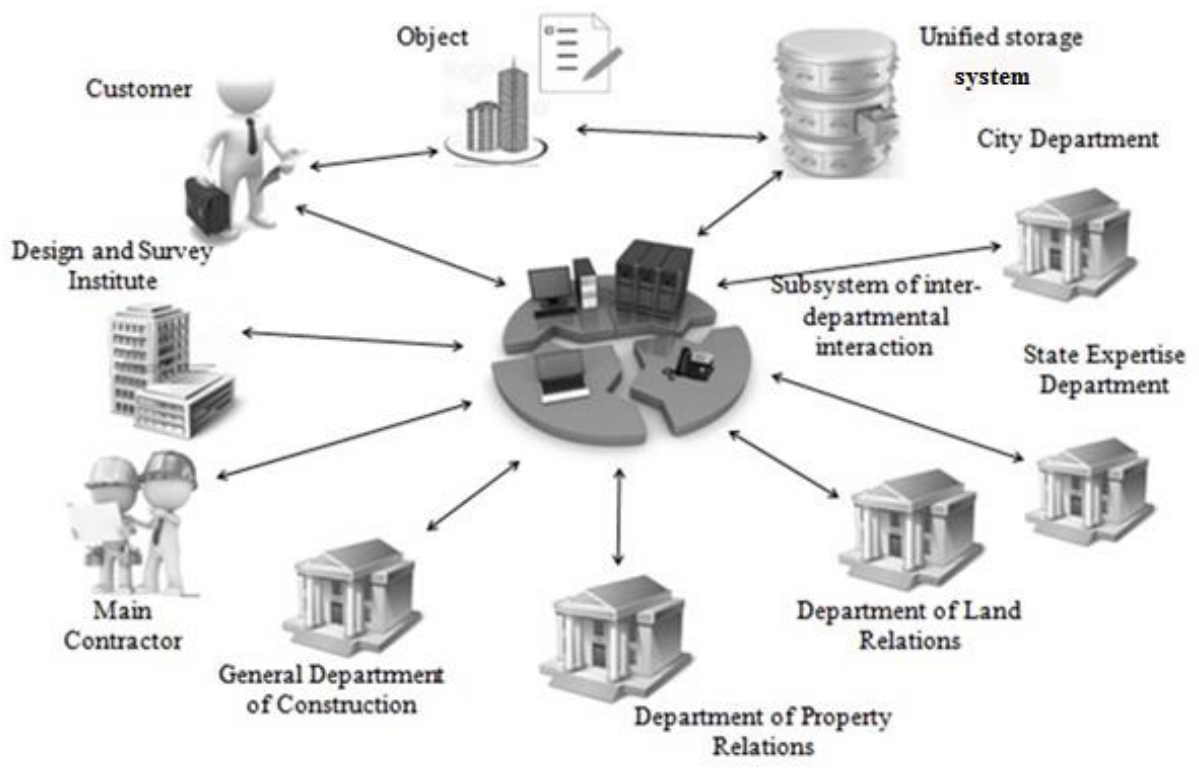

Fig. 4. The structure of the uniform virtual information space of construction organizations and enterprises of the Tyumen region.

The uniform information space consists of the following main components:

- information resources containing data, information and knowledge recorded on appropriate media;

- organizational institutes that ensure the functioning and development of the uniform information space, in particular the collection, processing, storage, dissemination, retrieval and transmission of information;

- means of information interaction between citizens and organizations, providing them the access to information resources based on appropriate information technologies including software and hardware and organizational and regulatory documents.

The organizational model of the interaction of the customer and construction organizations in the information space includes the interaction of the following parties: the 
customer, the general contractor, the departments, the General Department of Construction, the state expertise department and the design and survey institute; web-service, a subsystem of inter-departmental information volume and a united system of storage and management of integrated resource.

If the customer has the documents necessary to conclude a contract with the design and survey institute he needs to fill out the form using a web-service: select the appropriate department which is a module in the uniform virtual space. Having switched to the system of inter-departmental information exchange the application finds its addressee and the specialist of the department has a new task in the list of applications. The available information is ready for preview to the department which makes a decision about the conclusion of the contract and the information is placed into the storage system.

After the conclusion of the contract the design and survey institute receives full access to the data concerning the object and proceeds to the development of design estimates. This documentation is regulated by the legislation of the Russian Federation. At this stage of the work there is a repeated coordination of the documentation with the customer. Comments are processed in the form of return of documents for adjustments. As a result the complete design and estimate documentation agreed with the customer is displayed in the checklist and the system proceeds to the next stage.

\section{Conclusions}

The result of this work is the development of an information model of the uniform virtual space of construction organizations and enterprises which allows to ensure the quality and efficiency of implementation of all stages of the life cycle of the construction of buildings and structures. Each participant of the construction process has an operative and reliable access to the relevant information in accordance with the regulated level of access. Such a system will allow to have a single true and complete source of data to accumulate information about each stage of the object's life cycle from the initial project to the decommissioning documents.

\section{References}

1. S. Bolshakov, Vestnik, 10, 258-265 (2013).

2. URL: http://www.doc-online.ru/news/294/

3. URL: http://www.it-weekly.ru/it-news/tech/105609.html

4. URL: http://www.mysitex.com/main/platform/about.htm .

5. Resolution of the Government of the Russian Federation. The Rules for the definition and provision of technical conditions for connecting the construction object to engineering and technical networks, 11 (2014).

6. Regulations of the general department of construction of the Tyumen region. Annex to the Resolution of the Government of the Tyumen Region, No. 146-p (2009).

7. Regulations of the construction supervision departmenmt of the Tyumen region, No. 1135OD (2017).

8. V. Shumaev, O. Romanchenko, Moscow State University Bulletin of the name S. Y. Witte. Series 1. Economics and management, 2(13), 90-95 (2015).

9. URL: http://admtyumen.ru 
10. Regulations for the integrated support of investment projects implemented and (or) planned for implementation in the Tyumen region. The appendix to the order of the Government of the Tyumen region from February, N 248-rp., 21 (2013).

11. URL: http://www.nazametku.com/dlia-raboty/idef0-metodologiya-notaciya-principy$\underline{\text { model } /}$

12. V. Repin, V. Eliferov . Process approach to management. Modeling of business processes (Moscow, Mann, Ivanov and Ferber, 2013).

13. F. Popov, A. Maksimov, Polzunovsky vestnik 2, 127-133 (2006).

14. URL: http://texpert.info/building/osnovnyie-ponyatiya-proektirovaniya-obektastroitelstva/ (2012).

15. URL: http://projectimo.ru/upravlenie-proektami/stadii-investicionnogo-proekta.html

16. Resolution of the Government of the Russian Federation. The procedure for organizing and conducting state expertise of project documentation and the results of engineering surveys, 13 (2017).

17. URL: http://fb.ru/article/254264/arhitektura-seti-struktura-seti-peredachi-dannyih-ioborudovanie

18. P 50.1.028-2001. Information technologies of life cycle support of products. Methodology of functional modeling. 